\title{
Eufemismo e cumplicidade objetiva nos primórdios do campo educacional brasileiro. Um caso exemplar de $1860^{*}$
}

\author{
Gilson R. de M. Pereira**
}

\begin{abstract}
RESUMO: Com base na perspectiva de Bourdieu e consultando um texto de 1860 - Estudos sobre o ensino publico, Recife: Typ. Commercial de Geraldo Henrique de Mira \& C., de autoria de Aprigio Justiniano da Silva Guimarães -, o presente estudo analisa as ambigüidades relativas ao econômico e os mecanismos de "cumplicidade objetiva" presentes nos primórdios do processo de constituição e autonomização do campo educacional brasileiro.
\end{abstract}

Palavras-chave: Interesse, desinteresse, eufemismo, campo educacional

\section{Introdução}

O texto a seguir constitui recolho inicial de uma pesquisa destinada a apreender a forma específica de estratégia adequada aos jogos propriamente simbólicos praticados pelos agentes durante o processo de diferenciação e autonomização do campo educacional brasileiro. Com base na proposição segundo a qual as trocas que se dão nos campos simbólicos configuram uma modalidade de economia denegada, de economia antieconômica, na qual os agentes têm interesse no desinteresse (cf. Bourdieu 1994a, 1994b), o trabalho analisa as ambigüidades re-

\footnotetext{
* O autor foi beneficiado com as sugestões e críticas da professora e do professor Denice e Afrânio Catani, ambos da Faculdade de Educação da USP e deixa-Ihes aqui um agradecimento especial. Ambos não são responsáveis por eventuais erros e omissões do autor.

** Professor da Faculdade de Educação da Universidade Regional do Rio Grande do Norte (URRN).
} 
lativas ao econômico e os mecanismos de "cumplicidade objetiva" presentes num livro de 1860, hoje relegado ao limbo.

\section{Ambigüidades relativas ao econômico}

A ambigüidade presente simultaneamente na defesa de vencimentos que garantam boas condições materiais de vida e na proclamação, ora velada, ora explícita, da irredutibilidade econômica dos valores pertinentes à profissão de professor, aceitação e recusa do econômico com acentuado pendor para a utilização de termos evocando as imagens mais sublimes e os valores mais nobres, dignos e sérios para distinguir a profissão, parece ser um traço característico da constituição do campo educacional brasileiro, traço já identificável nos primórdios mesmo da instrução pública. Em "Memória Histórico-Pedagógica" apresentada à Faculdade de Direito do Recife no dia 2 de março de 1860 e publicada em Estudos sobre o ensino publico, Recife: Typografia Commercial de Geraldo Henrique de Mira \& C., 1860, o doutor Aprigio Justiniano da Silva Guimarães, lente substituto da mencionada instituição, reagia desse modo ao estado que, segundo ele, se encontrava o professorado:

Os professores do Curso preparatorio foram desapreciados pela reforma, quando deixaram-n'os na mesquinhez d'ordenados, em que vivem. Ha certas economias pelas quaes a posteridade votará anathemas aos nossos Estadistas... Dizer ao mestre - viverás na indigencia, se tomares ao serio o seu sacerdocio - não será um attentado contra a sociedade, uma curteza de vista deplorável? (Guimarães 1860, p. 41)

A referência ao sacerdócio não é, de modo algum, isolada. Ao longo de toda a obra, o autor fará constantes alusões à profissão docente em termos vazados como "apostolado", "a pureza do nosso sacerdócio", "sacerdócio perpétuo", "religião do dever", "sagrada missão", "sacerdotes do dever". Embora manifeste-se, de fato, muito religioso - o autor põe-se decididamente ao lado da religião e da educação como fontes da virtude -, tudo parece indicar que o que pesa nessas reiteradas referências aos deveres sagrados do magistério não é propriamente a religião, ou melhor, a carolice - 0 autor gaba-se de sua independência: "Desconfio de tudo quan- 
to o mundo applaude" (Guimarães 1860, p. 29), e recusa o ferrete tanto de jesuíta como de reformador ultramontano -, mas uma avaliação moral altamente favorável da educação e de sua profissão, avaliação balizada por elementos que encontram na linguagem dos valores mais sublimes, de altruísmo, renúncia e abnegação - "ha muita honra em soffrer" -, o canal possível e mais apropriado para extravasar a necessidade de afirmação profissional. Os indícios são também de que não se trata apenas de uma espécie de compensação psicológica pessoal ante a desvalorização da profissão, de suas parcas recompensas tanto pecuniárias quanto simbólicas, mas sobretudo de um esforço de demarcação do espaço profissional traduzido pela reiteração dos altos valores norteadores do campo. Isso pode ser reforçado ao considerarmos que o autor se bate pela autonomia pedagógica do campo: "Não se-tracta d'entregar o ensino aos padres, que a questão é de methodo" (Guimarães 1860, p. 14).

A importância do texto que vimos examinando, Estudos sobre $o$ ensino publico, de autoria de Aprigio Guimarães, que faz sobressair de modo quase exemplar toda a ambigüidade antes aludida, é proporcional à ousadia do autor ao dizer o indizível, ao trazer à luz do dia, para os seus pares-concorrentes, a verdade econômica da profissão:

É principio economico, que o salario do trabalhador deve valer o esforço dispendido, a perda irreparavel das forças, a garantia do futuro. (...) Aos operarios do ensino collocaram em tal posição? - não Ihes-dão ordenados, porque elles podem acumular occupações, ensinando-se-lhes assim, que estão authorisados a ser máus mestres. (...) Quem n'esta terra dirá, que podemos garantir o futuro dos nossos filhos, mesmo com a mais economica e bem regulada educação, dispondo apenas dos nossos ordenados? (Guimarães 1860, p. 71)

O doutor Aprigio, é necessário dizer, não era um qualquer. Era um jovem lente (tinha 29 anos) da prestigiosa Faculdade de Direito do Recife, de onde, um pouco mais tarde, despontaria a famosa "Escola do Recife". É possível que Silvio Romero tenha ouvido as suas preleções, que tenha sido colega de Tobias Barreto. Foi deputado pelo Ceará na Câmara dos Deputados nos anos de 1854 a 1856 e deputado na Assembléia Provincial de Pernambuco nas legislaturas de 1854 a 1855 e de 1863 a 1864, e em 1856 apresentou projeto de lei à Câmara dos Deputados sobre propriedade literária (Guimarães 1860, pp. 171-179). No discurso do doutor Aprigio é visível que ele, aparentemente, não tinha outros recursos para se manter senão os 
proporcionados pela sua profissão. Depreende-se também que o autor se batia na defesa dos que se encontravam na mesma posição. Era, por conseguinte, um profissional defendendo explicitamente remuneração adequada para o professorado, embora tendo sempre como limite referencial a dignidade intangível de seu mister, logo, a sua irredutibilidade às coisas econômicas mais comuns (prevalência das imagens sagradas no discurso). Ao pleitear remuneração adequada e dedicação exclusiva ao magistério, como se verá a seguir, o autor lutava para que os professores se livrassem dos "bicos" e das ocupações acumuladas a que estavam condenados os "maus mestres", como ele mesmo faz notar. A próxima passagem lança luz sobre o estado de ânimo nos primórdios da delimitação do campo educacional. É interessante observar as alusões à posição dominada ocupada pelos mestres em relação ao campo do poder, sendo preciso disputar, regatear prêmios e aceitá-los sob condições adversas, alusões que confirmam a dependência e a ainda muito reduzida autonomia do espaço profissional dos professores:

Eu quizera ser somente mestre, dar todos os meus dias á sagrada missão, que tanto ambicionei, e vejo-me em difficuldades de consegui-lo, porque haveria risco de faltar com o que devo aos meus filhos. O que nos offerecem em troca de tão util exclusivismo, que tanto se combina com as exigencias do ensino, que é o interesse primario do paiz?- Um pão demasiado escasso; e de tempos a tempos um premio magro para as nossas producções, e demais requerido, informado, disputado, regateado, e afinal dado com uma duzia de condições humilhantes, com os anginhos de uma censura, cujas bullas são muitas vezes suspeitas. $\left(^{*}\right)$ (Guimarães 1860, p. 72)

O rodapé correspondente ao asterisco diz, com veemência bastante pronunciada, o seguinte: "Maldita a economia do prodigo, que exerce-se sobre o necessário em favor do superfluo, até que a penúria chega! E porque tanta parcimonia comnosco?" E adiante, arrebatado, castiga com ironia: "Feliz imperio da Santa-Cruz, como é barato o teu futuro!" (Guimarães 1860, p. 72).

\section{Eufemismos e cumplicidade objetiva}

Como foi recebida a locução do doutor Aprigio? Como os seus pares-concorrentes reagiram à explicitação da verdade econômica da "nobre profissão"? O autor nos indica: 
Mas... Parece-me, meus illustres collegas, que ouço uma sublime reprehensão de vossa consciencia e dignidade! Sim; risco tudo quanto escrevi sobre este ponto, e acompanho-vos no alto empenho d'esquecer os motivos das queixas, para tacitamente darmos a mais solemne resposta, não deslisando-nos da linha do nosso dever. (Guimarães 1860, pp. 72-73)

É possível que a reação tenha sido maior do que uma "sublime repreensão". Tanto que o autor ameniza o que disse, prontificando-se a riscar tudo, e volta ao assunto, em nota suplementar, notificando que alguns amigos censuraram-Ihe "a agrura da fórma". Mantém-se firme, no entanto: "Mas, fico contente de terem todos razão contra mim quanto á fórma, com tanto que eu tenha razão contra todos quanto á substancia" (Guimarães 1860, p. 77). É notável que a questão tenha sido colocada em termos de forma, pois, assim, flagra-se um momento de construção dos eufemismos do campo educacional. Como se sabe, esse trabalho de eufemização resulta de uma espécie de compromisso entre o que se quer dizer e o que se pode dizer, ou seja, entre a intenção da palavra, condicionada pela posição no campo e pela trajetória que a conduz, e as condições de recepção do discurso, determinadas pela estrutura da distribuição dos capitais do campo: "toda expressão é um ajuste entre um interesse expressivo e uma censura constituída pela estrutura do campo ao qual se oferece esta expressão, e este ajuste é o produto de um trabalho de eufemização, podendo ir até ao silêncio, limite do discurso censurado" (Bourdieu 1984a, p. 138). Desse modo, o campo funciona "como censura" e pode-se até afirmar que quanto mais autônomo é o campo, mais específicas são as censuras que lhe são próprias. Em um campo altamente autônomo como o filosófico, Heidegger pôde-se valer de palavras como "autêntico" e "inautêntico" para classificar o legítimo e o ilegítimo filosóficos, censuras decerto incompreensíveis para outros campos (Bourdieu 1984a). Em campos menos autônomos ou em processo de autonomização - a autonomização de um campo coincide tanto com a criação de uma rede mais ou menos extensa de instituições concorrentes quanto com a construção dos eufemismos que põem os discursos nas formas aceitas, adequadas, legítimas -, as censuras são, por assim dizer, mais dispersas e genéricas e, no caso do campo educacional brasileiro, inclinadas a fazer apelo à dimensão moral. 
Os campos, segundo Bourdieu (1984b), são determinados pela definição dos jogos e das apostas que neles se fazem presentes. Os jogos e interesses de cada campo, em particular, são irredutíveis aos jogos e interesses dos outros campos, mas a propriedade geral, discernível, é o fato de que todos os campos são espaços de lutas por meio dos quais os agentes do campo mobilizam recursos adequados aos interesses em jogo. Os jogos e as apostas característicos do campo possuem uma unidade garantida por seus interesses fundamentais: se um agente está preso aos jogos de determinado campo, ou seja, se está imbuído da ilusão necessária para participar e fazer o campo funcionar, é razoável supor que ele não apostaria em um ganho cuja conseqüência prática fosse a destruição do próprio jogo ou a sua exclusão (é o que Bourdieu chama de "cumplicidade objetiva"). A permanência do jogo, reforçado e atualizado pelas lutas em que se disputam as posições-chave, por meio das quais se pode enunciar o legítimo e o ilegítimo no campo, é garantida pelo habitus específico do campo, princípio de ação incorporado pelos agentes e que está na base do conhecimento e do reconhecimento das coisas pertinentes ou não nas lutas do campo. Embora a recompensa material dos professores fosse importante para o doutor Aprigio, a ponto de o fazer ironizar o governo do Império, suprema ousadia para um monarquista liberal, o autor mostra-se prontamente disposto a riscar tudo, a esquecer os motivos das queixas e a dar, tacitamente, uma solene resposta, alta, digna, não se afastando do cumprimento do "sagrado dever". Enquanto novato (o doutor Aprigio leu a sua aula inaugural, na cadeira de Economia Política, em 24 de setembro de 1859, um ano antes da publicação dos Estudos), o autor revela-se mais inclinado a lances ousados, quase de escândalo, a fazer afirmações capazes de incomodar a dignidade dos colegas. Ao novato é visível - ele que não sabia transigir com o que lhe parecia "aberração da verdade e da justiça" - faltar o pleno domínio do sentido do jogo, dos eufemismos usados, habilidade, Ihaneza, linguagem sutil capaz de dizer não dizendo, o conjunto das disposições suficientemente incorporadas capazes de fazer os interesses externarem-se como desinteressados. Enfim, ao autor faltavam as disposições que permitissem enunciar de forma adequada os motivos do jogo, condição e produto do funcionamento do campo, que prendia a todos os que faziam o campo funcionar, embora na época em processo ainda muito incipiente de diferenciação. Observe-se que, como novato, logo, dotado de reduzido capital simbólico, o autor, em que pese os lances ousados, ocupa posição dominada no campo acadêmico. Prova disso é a referência feita pelo autor ao senhor doutor Pertence, professor da Faculdade de Medicina da Corte, que teria igualmente clamado 
veementemente contra as más condições do trabalho docente. As reclamações do doutor Pertence, queixa-se o autor, tiveram êxito e as dele, não. Percebe-se nitidamente a diferença: de um lado, um novato, pouco capital simbólico, linguagem penalizada sob "agruras da forma" e, de outro, um professor sob "regimem d'Estatutos", consolidado na carreira, fato que the valia viagens à Europa e que podia "mudar a hora da sua aula sem humilhação", dispondo "d'elegancia de linguagem". Questão de posições e de poderes.

\section{Trajetória e posição no campo}

É possível inferir, pelas referências feitas às dificuldades encontradas para obter o posto de professor do ensino superior, que o autor, se não necessariamente de origens humildes, positivamente não pertencia à juventude dourada de seu tempo:

a fadiga ia consumindo-me o corpo, o scepticismo ia devastando-me o espirito (...). Apresentei-me em concurso, rejeitaramme. (...) Apresentei-me em $2^{\circ}$ concurso, achei-me só, retireime. Em 3ํ já fui mais feliz, coube-me o segundo lugar. Em $4^{\circ}$ mantiveram-me neste posto. Afinal, depois de tão longa fadiga, a Justiça Imperial coroou meus esforços (Guimarães 1860, pp. 104-107).

A percepção das coisas em jogo no campo (científico, artístico, educacional etc.) depende tanto da posição ocupada pelo agente quanto da trajetória que a ela conduz, mediatizada pelo sucesso escolar (Bourdieu 1975). Os campos simbólicos possuem as propriedades anteriormente apontadas, a da irredutibilidade dos interesses e das apostas - "não se poderá fazer correr um filósofo com os motivos dos geógrafos" (Bourdieu 1984b, p. 114) - e a de serem espaços de lutas concorrenciais em torno dos valores e interesses do campo. Mas talvez a mais notável e surpreendente propriedade dos campos simbólicos seja a recusa do econômico, valorizada em especial nos campos simbólicos mais esotéricos (matemática pura, arte de vanguarda etc.), mas igualmente presente em campos como o educacional, embora relativamente sensível às demandas externas, e praticamente de- 
saparecendo em campos como o do jornalismo e da indústria cultural, bastante abertos à lógica propriamente econômica. As trocas que ocorrem nos campos simbólicos mais puros são trocas que compõem uma modalidade de economia denegada, de economia antieconômica. Nessas trocas, os ingredientes são os seguintes: os agentes entram "intencionalmente sem intenção", ou seja, sem cálculo consciente, mas, ao mesmo tempo, previamente predispostos, pelo habitus incorporado, a entrar num jogo cuja verdade (de troca e de domínio simbólico) é encoberta por eufemismos sutis. Nas trocas simbólicas, justamente porque as ações dos agentes são guiadas por todas as disposições que os ligam ao intercâmbio simbólico, ou seja, pelo habitus que não os faz indiferentes aos jogos e às apostas específicos envolvidos, os agentes têm interesse no desinteresse. Quanto mais livre das urgências cotidianas, quanto mais bem situado no campo, quanto mais capital simbólico possui o agente, mais ele se mostrará inclinado a proclamar a irredutibilidade econômica do fato simbólico (estético, científico etc.). Quanto mais imerso está o agente nas regras de determinado campo simbólico, mais inclinado se mostrará a apresentar suas ações como livres de injunções alheias aos propósitos específicos do campo, ou seja, como desinteressadas. Quanto mais convencido está o agente dos valores do campo simbólico, quer dizer, quanto mais oblato, mais insensível se mostrará às demandas externas (na forma, por exemplo, de reconhecimento mundano). No caso do doutor Aprigio, e sua exemplaridade reside nisso, a posição no campo, a trajetória acidentada que a conduz e as origens sociais inclinam o autor, "um obreiro do ensino", como ele mesmo se classifica, a expor as urgências, sem cinismo nem cálculo consciente, daí a origem das ambigüidades, mas também com franqueza, premido pela necessidade - permitindo-nos afirmar que para este caso também vale a proposição segundo a qual quanto mais reduzido é o grau de liberdade em relação às necessidades cotidianas, quanto menos bem situado no campo, quanto menos capital simbólico possui o agente, mais ele se mostrará inclinado a proclamar a verdade econômica do fato simbólico (estético, científico etc.). A dificuldade do autor de Estudos sobre o ensino publico em usar de eufemismos reside na forma de apreensão e ordenamento do mundo, ou seja, na sua relação prática com o campo educacional e em todo o conhecimento em estado prático daí advindo. Para o jovem doutor Aprigio, o mundo - com suas tarefas, trabalhos e canseiras - impunha a sua presença sob a forma de necessidades. 


\section{Considerações finais}

É preciso reconhecer que se o estudo do texto do doutor Aprigio, como feito até aqui, lança luz nos jogos simbólicos praticados na estrutura latente do campo educacional brasileiro em meados do século passado, possui o inconveniente de não se prestar a conclusões mais gerais. Para isso seria necessário um material empírico mais vasto e a recorrência a uma análise sincrônica de textos originados com base em diferentes posições no campo. Mas, lembrando a exemplaridade do Estudos sobre o ensino publico, é possível trabalhar com a hipótese de que as tendências mais marcantes do texto, caso não se tratem apenas, como supomos, de idiossincrasias pessoais, apresentem-se nitidamente configuradas no começo do século $\mathrm{XX}$, o período dos "educadores à meialuz", na feliz expressão de Denice Catani (1989), uma época certamente decisiva do processo de delimitação dos espaços profissionais e de diferenciação e autonomização do campo educacional brasileiro, de construção da rede de escolas e de formação sistemática dos agentes, enfim, uma época de fixação das apostas, dos jogos e das regras, da criação de objetos legítimos e legitimáveis pelos quais se bater e da escoIha de valores e linguagem legítimos ao campo.

\section{Euphemism and objective complicity in the early brazilian educational area, an examplar case from 1860}

ABSTRACT: From Bourdieu's perspective and under the consultation of a text written by Aprigio Justiniano da Silva Guimarães in 1860: Estudos sobre o ensino publico, Recife: Typ. Commercial de Geraldo Henrique de Mira \& C., the study analyses the ambiguity connected with the economic and mechanism of "objective complicity" present in the beginning of the constitution and autonomyzation process of Brazilian educational area.

\section{Bibliografia}

BOURDIEU, Pierre. "Méthode scientifique et hiérarchie sociale des objets". Actes de la Recherche en Sciences Sociales, $\mathrm{n}^{\circ}$ 1, jan. 1975, pp. 4-6. 
. "La censure". In: . Questions de sociologie. Paris:

Minuit, 1984a, pp. 138-142.

. Quelques propriétés des champs. In: . Questions de sociologie. Paris: Minuit, 1984b, pp. 113-120.

. "L'économie des biens symboliques". In: Raisons pratiques. Sur la théorie de l'action. Paris: Seuil, 1994a, pp. 175-213. . "Un acte désintéressé est-il possible?". In: . Raisons pratiques. Sur la théorie de l'action. Paris: Seuil, 1994b, pp. 175213.

CATANI, Denice B. "Educadores à meia-luz: Um estudo sobre a Revista de Ensino da Associação Beneficente do Professorado Público de São Paulo". Tese de doutoramento. São Paulo: FEUSP, 1989.

DICIONÁRIO BIOGRÁFICO DE PERNAMBUCANOS CÉLEBRES. F. A. Pereira da Costa. Recife: Fundação de Cultura Cidade do Recife, 1982 (fac-símile da edição de 1882).

ENCICLOPÉDIA DE LITERATURA BRASILEIRA. Afrânio Coutinho et. al. Rio de Janeiro: FAE, 1989, 2v.

GUIMARÃES, Aprigio Justiniano da Silva. Estudos sobre o ensino publico. Recife: Typografia Commercial de Geraldo Henrique de Mira \& C., 1860.

MOACYR, Primitivo. A instrução e as províncias. São Paulo: Companhia Editora Nacional, v. 1, 1939. 